\title{
Intersectional social-economic inequalities in breast cancer screening in India: analysis of the National Family Health Survey
}

Jyotsna Negi ${ }^{*}$ and Devaki Nambiar ${ }^{2,3,4}$

\begin{abstract}
Background: Breast cancer incidence rates are increasing in developing countries including India. With 1.3 million new cases of cancer been diagnosed annually, breast cancer is the most common women's cancer in India. India's National Family Health Survey (NFHS-4) data 2015-2016 shows that only 9.8\% of women between the ages of 15 and 49 had ever undergone breast examination (BE). Further, access to screening and treatment is unequally distributed, with inequalities by socio-economic status. It is unclear, however, if socio-economic inequalities in breast examination are similar across population subgroups.

Methods: We compared BE coverage in population sub-groups categorised by place of residence, religion, caste/ tribal groups, education levels, age, marital status, and employment status in their intersection with economic status in India. We analysed data for 699,686 women aged 15-49 using the NFHS-4 data set conducted during 2015-2016. Descriptive (mean, standard errors, and confidence intervals) of women undergoing BE disaggregated by dimensions of inequality (education, caste/tribal groups, religion, place of residence) and their intersections with wealth were computed with national weights using STATA 12. Chi-square tests were performed to assess the association between socio-demographic factors and breast screening. Additionally, the World Health Organisation's Health Equity Assessment Toolkit Plus was used to compute summary measures of inequality: Slope index for inequality (SII) and Relative Concentration Indices (RCI) for each intersecting dimension.
\end{abstract}

Results: BE coverage was concentrated among wealthier groups regardless of other intersecting population subgroups. Wealth-related inequalities in BE coverage were most pronounced among Christians (SIl; 20.6, 95\% Cl: 18.5-22.7), married (SII; 14.1, 95\% Cl: 13.8-14.4), employed (SII: 14.6, 95\%Cl: 13.9, 15.3), and rural women (SII; 10.8, 95\% Cl: 10.5-11.1). Overall, relative summary measures (RCI) were consistent with our absolute summary measures (SII).

Conclusions: Breast examination coverage in India is concentrated among wealthier populations across population groups defined by place of residence, religion, age, employment, and marital status. Apart from this national analysis, subnational analyses may also help identify strategies for programme rollout and ensure equity in women's cancer screening.

Keywords: India, Breast cancer screening, Inequalities

*Correspondence: negi.jyotsna20@gmail.com

${ }^{1}$ Independent Consultant, 62 Stratford Rd, Kensington, California 94707, USA

Full list of author information is available at the end of the article

\section{Background}

Cancer is the second most common cause of death globally, accounting for 9.6 million deaths in $2018,70 \%$ of which occurred in Low- and Middle-Income Countries (LMICs) [1]. Breast Cancer (BrCa) is the leading cause 
of cancer mortality in women worldwide [2, 3] and burden is increasing in LMICs [4]. Although $\mathrm{BrCa}$ can be detected at earlier stages by simple breast examination and is treatable, most Brca cases are diagnosed very late [5]. This is particularly a matter of great concern in LMICs where $\mathrm{BrCa}$ often results in higher morbidity and financial constraints to households as compared to high income countries. For instance, although, the estimated number of new breast cancer cases diagnosed in the USA [6] is 1.6 times those diagnosed in India [7] in the year 2020 , the estimated number of deaths due to $\mathrm{BrCa}$ in India is twice the deaths in the USA. ${ }^{1}$ With $1,78,361$ new cases diagnosed and 90,408 deaths in the year 2020, $\mathrm{BrCa}$ is the most common form of cancer affecting women in India [7]. Nevertheless, most women remain unscreened, and late diagnosis is common: survival rates of women with $\mathrm{BrCa}$ range from 25.3 to $48.4 \%$ in India, much lower than other Asian countries like China (57.6-82.3\%), Thailand (55.8-63.6\%), and the Philippines (34.7-51.9\%) [8]. India's National Family Health Survey (NFHS-4) data 2015-2016 for the first time collected data on $\mathrm{BrCa}$ screening: it found that only one in ten women between the ages of 15 and 49 in India had ever undergone breast examination [9].

The goal of screening for $\mathrm{BrCa}$ is to identify signs of breast cancer among all women even before the symptoms appear [10]. The key to control BrCA's outcome and improve survival rates is awareness generation and early detection to promote early diagnosis and screening of $\mathrm{BrCa}$ [11]. Breast cancer detected at an early stage is found to be associated with a reduction in cancer deaths across many study designs [10]. In a recent Indian trial, biannual clinical breast examinations were found to be associated with a $30 \%$ reduction in cancer mortality among those aged 50 and older [12]. In India, until 2016, there was no national population-based breast cancer screening programme [5], and most women seeking mammography went to the private sector, or had to rely on opportunistic screening under the National Programme for Prevention and Control of Cancer, Diabetes, Cardiovascular diseases and Stroke for diagnosis in the public sector [8]. In light of this, Government of India formulated a population based cancer-screening program in 2016 where all women above age 30 were eligible for regular breast, cervix and oral cancer screening [13]. Population-based screening programmes are intended to assure more equity in access in comparison with other health initiatives such as opportunistic screening

\footnotetext{
${ }^{1}$ In 2020, an estimated 276,480 and 178,361new BrCa cases were diagnosed in the USA and India respectively. The estimated deaths due to $\mathrm{BrCA}$ were 42,170 in the USA and 90,408 in India.
}

programmes [3]. However, social inequalities in access can still be observed in population-based programmes [4], as disadvantaged populations are at high risk but end up being excluded [5].

Previous studies on BrCa screening published mostly in the developed world have found that several socioeconomic, demographic, and geographic variables are associated with breast cancer screening. Similarly, some studies from the developing world also show that socioeconomic determinants such age, education, marital status, and income-are important determinants associated with the likelihood of receiving breast cancer screening $[4,14-20]$.

$\mathrm{BrCa}$ in its earliest stages is painless and produces masses; women from low socioeconomic groups, and/or with low levels of education tend not to seek care even when after noticing a lump for fear of facing rejection by family and community, fear of job loss, hesitancy of discussing breast cancer topic with family, fear of having to face surgery and in turn catastrophic health expenditures, fear of dying due to the disease and the notion that the condition is incurable [5]. A 2006 study in Trivandrum, Kerala found that Muslim women, unmarried women and those with professional occupation (other than manual) were less likely to undergo clinical breast examination as compared to Hindu women, married women and homemakers [16]. There is further evidence that age [21], social economic status, marital status, education [22] and health status may have an impact on the patterns of women undergoing breast screening $[5,14]$. In addition, several studies among Indian women reported that religion and caste are barriers to BrCa screening uptake [23]. There is also evidence that rural women are less likely than urban women to go for breast screening $[2,24]$.

Most of these studies have a small sample size and do not look at the interplay of factors affecting breast cancer screening. Income has been reported as a significant determinant in undergoing breast cancer screening in almost all studies but there is no study to our knowledge that examines income inequalities within subgroups by age, education, religion, caste and other factors that may influence screening uptake. Filling this gap, in this paper we sought to examine the magnitudes and intersections of wealth related inequalities among women who reported ever undergoing breast examination in India with other dimensions of inequality.

\section{Methods}

Our analysis sought to examine inequalities related to education, place of residence, religion, caste and tribal status, education, age, employment status and marital status in self-reported breast examination among different wealth groups using double disaggregation. Data 
Table 1 Illustrative matrix of subgroups

\begin{tabular}{lllllll}
\hline Religion & Poorest (Pt) & Poor (Pr) & Middle (M) & Richer (Rr) & Richest (Rt) & Wealth difference within religion subgroups \\
\hline Hindu (H) & $\mathrm{HPt}$ & $\mathrm{HPr}$ & $\mathrm{HM}$ & $\mathrm{HRr}$ & $\mathrm{HRt}$ & Slope Index of Inequality and Relative Concentration Indices to \\
Muslim (M) & $\mathrm{MPt}$ & $\mathrm{MPr}$ & $\mathrm{MM}$ & $\mathrm{MRr}$ & $\mathrm{MRt}$ & measure income related inequalities within respective religion \\
Christian(C) & $\mathrm{CPt}$ & $\mathrm{CPr}$ & $\mathrm{CM}$ & $\mathrm{CRr}$ & $\mathrm{CRt}$ & \\
Sikh/Bud- & $\mathrm{OPt}$ & $\mathrm{OPr}$ & $\mathrm{OM}$ & $\mathrm{ORr}$ & $\mathrm{Ort}$ & \\
dhist/Others & & & & & & \\
$(\mathrm{O})$ & & & & & & \\
\hline
\end{tabular}

analysed for this study was secondary data sourced from National Family Health survey (NFHS), fourth round, conducted during 2015-2016. This survey comprised a nationally representative sample of household: 699,686 women were interviewed using a multistage sampling design. NFHS 4 collected data on socio demographic characteristics of members of the households like age, education, occupation, marital status; household information such as religion, caste and tribal status, electricity, water and sanitation, insurance; as well as health related indicators like experiences with reproductive and child health service delivery, non-communicable disease related risk factors and health seeking. Information regarding ever undergone $\mathrm{BE}$, an indicator for breast cancer screening coverage, was collected from women age 15-49 in each selected household. The question asked was "have you ever undergone breast examination?". We constructed a binary variable for $B E$ with a value of 1 if the respondent reported ever undergoing $\mathrm{BE}$, and 0 if not.

\section{Dimensions of inequality}

The dimensions of inequality selected in this paper were: place of residence, religion, caste/tribal groups, education, age, employment and marital status across wealth quintiles based on the existing literature on screening and health inequalities in India [2, 14, 16-19]. Wealth quintiles were constructed by way of a principal component analysis using an asset index of household assets such as fan, television, car, scooter, animals and land. Wealth quintiles were used as proxy to socioeconomic status of households. Four dummy variables of education attainment were created: no education, primary education, secondary education, and higher levels education. Four dummy variables of caste and tribal group were created (Scheduled Tribe, ST; Scheduled Caste, SC;'Other Backward Classes, OBC; and General) as per convention [25]. Four dummy variables of religion were created: Hindu, Muslim, Christian, and 'Sikh, Buddhist, and others'. Age was grouped into four categories: 15-24, 25-29, 30-34, 35-49, Employment status was a binary variable: not being employed was coded as 1 and zero otherwise and last, marital status was also a binary variable where being currently married was coded as 1 and zero otherwise.

We categorised each of the seven dimensions (place of residence, religion, caste/tribal groups, education, age, employment and marital status) by wealth quintile (poorest, poor, middle, richer and richest groups) such that each group had five sub dimensions. That is, sub groups were created like religion differences among poor, following intersectional quantitative methods used in Indian datasets previously [26, 27]. This is illustratively explained for the dimension of religion in Table 1 and provided for the entire analysis in Table 2. For example, poorest Hindu women to richest Hindu women, poorest Muslim women to richest Muslim women and so on.

Descriptive (mean, standard errors and 95\% confidence intervals) of women undergoing BE disaggregated by seven dimensions of inequality and their intersections with wealth were obtained. Chi square tests were used to find the associations between BE and selected dimensions. All descriptives were computed in STATA 12 [28] with national sampling weights for women applied using the svy command to account for varying response rates among the sampled population. In order to understand inequalities within wealth subgroups, we computed both the absolute Slope Index of Inequality (SII) and Relative Concentration Index (RCI) within each sub dimension of inequality using the World Health Organisation's Health Equity Assessment Toolkit (HEAT) Plus [29]. SII, an absolute and complex summary measure of inequality, is regression based and calculated by regressing on health outcomes with the relative position of subgroups. On the other hand, $\mathrm{RCI}$ is a relative summary measure that displays the concentration of the health variable in the distribution of population ranked by wealth and was multiplied by 100 for easier interpretation. For further understanding of these summary measures, please refer to the HEAT plus technical notes [30]. We also conducted a multivariate logistic regression to identify the relationship between our dependent variable $\mathrm{BE}$ and selected dimensions of inequality as indicated in Additional file 1. This study did not involve human subjects research and was conducted using publicly available data. 
Table 2 Demographic characteristics of women in the survey by wealth quintiles represented by N (\%), NFHS 2015-2016

\begin{tabular}{|c|c|c|c|c|c|}
\hline Dimension & Poorest & Poor & Middle & Richer & Richest \\
\hline \multicolumn{6}{|l|}{ Place of residence } \\
\hline Urban & $6411(2.6)$ & $15,577(6.4)$ & $37,118(15.3)$ & $74,359(30.7)$ & $108,759(44.9)$ \\
\hline Rural & $117,643(25.7)$ & $121,323(26.5)$ & $106,696(23.3)$ & $73,619(16.1)$ & $38,180(8.3)$ \\
\hline \multicolumn{6}{|l|}{ Religion } \\
\hline Hindu & $104,671(18.6)$ & $112,649(20)$ & $117,153(20.8)$ & $115,481(20.5)$ & $113,784(20.2)$ \\
\hline Muslim & $15,551(16.1)$ & $18,969(19.7)$ & $19,648(20.4)$ & $23,264(24.1)$ & $19,028(19.7)$ \\
\hline Christian & $1677(10.1)$ & $2555(15.4)$ & $3603(21.7)$ & $4158(25)$ & $4627(27.8)$ \\
\hline Other (Sikh/Buddhist etc.) & $2155(9.4)$ & $2727(11.9)$ & $3410(14.9)$ & $5074(22.2)$ & $9500(41.5)$ \\
\hline \multicolumn{6}{|l|}{ Caste } \\
\hline Scheduled Tribe & $26,305(41)$ & $16,864(26.3)$ & $10,265(16)$ & $6692(10.4)$ & 4019 (6.3) \\
\hline Scheduled Caste & $32,627(22.9)$ & $33,918(23.8)$ & $32,558(22.8)$ & $25,910(18.2)$ & $17,607(12.3)$ \\
\hline Other Backward Caste & $48,362(15.9)$ & $57,517(18.9)$ & $65,826(21.7)$ & $70,898(23.3)$ & $61,234(20.2)$ \\
\hline General & $13,143(8.1)$ & $22,740(14)$ & $29,373(18.1)$ & $38,444(23.7)$ & $58,566(36.1)$ \\
\hline \multicolumn{6}{|l|}{ Education } \\
\hline No education & $70,274(36.6)$ & $51,568(26.8)$ & $37,826(19.7)$ & $23,412(12.2)$ & $9055(4.7)$ \\
\hline Primary & $18,613(21.3)$ & $22,856(26.2)$ & $21,177(24.3)$ & $16,265(18.6)$ & $8322(9.5)$ \\
\hline Secondary & $33,752(10.2)$ & $57,952(17.5)$ & $75,046(22.7)$ & $87,400(26.4)$ & $76,887(23.2$ \\
\hline Higher & $1415(1.6)$ & $4524(5.1)$ & $9766(10.9)$ & $20,901(23.4)$ & $52,676(59)$ \\
\hline \multicolumn{6}{|l|}{ Age group } \\
\hline $15-19$ years & $25,257(20.8)$ & $27,378(22.5)$ & $25,999(21.4)$ & $23,379(19.2)$ & $19,540(16.1)$ \\
\hline 20-24 years & $19,666(16)$ & $24,486(19.9)$ & $26,522(21.6)$ & $27,177(22.1)$ & $25,114(20.4)$ \\
\hline $25-34$ years & $37,913(17.9)$ & $39,408(18.6)$ & $42,751(20.2)$ & $45,497(21.5)$ & $46,243(21.8$ \\
\hline $35-49$ years & $41,219(16.9)$ & $45,629(18.7)$ & $48,542(19.9)$ & $51,926(21.3)$ & $56,042(23)$ \\
\hline \multicolumn{6}{|l|}{ Employment status } \\
\hline Not in workforce & $11,445(14.2)$ & $13,951(17.3)$ & $15,962(19.8)$ & $18,545(23)$ & $20,846(25.8$ \\
\hline Others & $7271(21.2)$ & $7696(22.4)$ & 7857 (22.9) & $6439(18.8)$ & $5057(14.7)$ \\
\hline \multicolumn{6}{|l|}{ Marital status } \\
\hline Currently married & $92,919(18.2)$ & $100,910(19.7)$ & $104,665(20.5)$ & $107,455(21)$ & $105,425(20.6)$ \\
\hline $\begin{array}{l}\text { Others (unmarried-widowed- } \\
\text { separated) }\end{array}$ & $31,135(16.5)$ & $35,990(19.1)$ & $39,150(20.8)$ & $40,524(21.5)$ & $41,515(22)$ \\
\hline
\end{tabular}

\section{Results}

We found that the percentage of women belonging to 'poorest category' in rural dwellings was 9 times greater than those in urban dwellings. The percentage of women belonging from poorest to richest quintile ranged from 3 to $45 \%$ respectively in urban areas and from $26 \%$ in poorest quintile to $8 \%$ in richest quintile in rural areas. As expected, the poorest quintile had a disproportionate concentration of uneducated, ST and unemployed women while the richest quintile had more of urban, Sikh/Buddhist/other religion, general caste, highly educated and employed women. Detailed demographic characteristics of the sample disaggregated by wealth and its intersecting with other dimensions of inequalities (place of residence, religion, caste and tribal group, education, age, employment and marital status) are presented in Table 2.

\section{Descriptive statistics}

Mean and 95\% confidence interval of those undergoing $\mathrm{BE}$ by wealth intersecting with other dimensions of inequalities (place of residence, religion, caste and tribal group, education, age, marital status and employment) are presented in Table 3.

Overall, about $9.7 \%$ of women aged $15-49$ had ever undergone a breast examination. This percentage varied by different socio-economic dimensions. Poorest to Richest $\left(\mathrm{q}_{1}-\mathrm{q}_{5}\right)$ gap in BE coverage in rural India was 10.6 percentage points while it was 7.8 percentage points in urban India (see Fig. 1 and Table 3). BE coverage was 3 times higher in rural richest quintile than the rural poorest quintile while this ratio was 2.5 in urban areas. $\mathrm{BE}$ coverage was lowest among Muslims and highest among 'other' religion in the poorest quintile. The Absolute $\mathrm{q}_{5}-\mathrm{q}_{1}$ difference was highest among Christians (15.5), followed by married women (11.3) and lowest among 15-19 age 
Table 3 Descriptive analysis and summary measures for breast cancer screening coverage using NFHS 2015-2016

\begin{tabular}{|c|c|c|c|c|c|c|c|}
\hline Dimension & Poorest & Poor & Middle & Richer & Richest & SII & $\mathrm{RCl}$ \\
\hline \multicolumn{8}{|l|}{ Place of residence } \\
\hline Urban & $5.4(4.4-6.4)$ & $7.8(6.7-9)$ & $10.7(9.7-11.6)$ & $11.4(10.8-12)$ & $13.2(12.6-13.8)$ & $6.1(5.7-6.6)$ & $7.5(7.3-7.8)$ \\
\hline Rural & $5.3(5.1-5.5)$ & $7.3(7-7.6)$ & $9.5(9.2-9.8)$ & $12(11.6-12.5)$ & $15.8(15.2-16.5)$ & $10.8(10.5-11.1)$ & $19.4(19-19.7)$ \\
\hline \multicolumn{8}{|l|}{ Religion } \\
\hline Hindu & $5.5(5.2-5.7)$ & $7.6(7.3-7.9)$ & $9.9(9.5-10.2)$ & $11.6(11.2-12)$ & $13.1(12.7-13.6)$ & $9.7(9.4-9.9)$ & $15.9(15.6-16.2)$ \\
\hline Muslim & $3.9(3.4-4.4)$ & $5.5(4.9-6.1)$ & $8(7.1-9)$ & $10.5(9.7-11.4)$ & $13.6(12.6-14.7)$ & $12.2(11.6-12.9)$ & $22.2(21.2-23.2)$ \\
\hline Christian & $5.1(3.9-6.3)$ & $6.2(5.1-7.4)$ & $10(8.5-11.5)$ & $14.5(12.7-16.3)$ & $20.6(18.5-22.7)$ & $20.8(18.8-22.7)$ & $24.4(22.8-25.9)$ \\
\hline Other & $6.4(4.7-8.2)$ & $12.2(9.6-14.8)$ & $17.5(14.8-20.2)$ & $17.9(15.3-20.5)$ & $20.1(18.5-21.7)$ & $13.6(11.8-15.4)$ & $11.9(11.2-12.6)$ \\
\hline \multicolumn{8}{|c|}{ Caste and tribal group } \\
\hline ST & $6.4(5.9-6.9)$ & $9.1(8.4-9.9)$ & $10.2(9.3-11.1)$ & $11.1(9.8-12.5)$ & $11.8(9.2-14.4)$ & $7(6.2-7.7)$ & $12.4(11.9-13)$ \\
\hline SC & $4.9(4.5-5.2)$ & $7.6(7.1-8.2)$ & $10.4(9.7-11.1)$ & $12.1(11.2-13)$ & $13.5(12.4-14.7)$ & $10.8(10.2-11.3)$ & $18.5(17.9-19.1)$ \\
\hline $\mathrm{OBC}$ & $5(4.7,5.3)$ & $6.8(6.5,7.1)$ & $9.5(9.1,9.9)$ & $12(11.5,12.5)$ & $14.3(13.7,14.9)$ & $11.7(11.3,12.1)$ & $18.7(18.4,19.1)$ \\
\hline General & $5.3(4.7,5.9)$ & $7.4(6.6,8.1)$ & $9.8(9,10.6)$ & $11.3(10.6,12)$ & $13.8(13.1,14.5)$ & $10(9.5,10.6)$ & $13.9(13.5,14.3)$ \\
\hline \multicolumn{8}{|l|}{ Education } \\
\hline No education & $5.8(5.5,6.1)$ & $8.4(8,8.8)$ & $10.8(10.2,11.4)$ & $12.4(11.6,13.2)$ & $14(12.7,15.3)$ & $9.5(9,9.9)$ & $16.9(16.5,17.3)$ \\
\hline Primary & $5.3(4.9,5.7)$ & $8.5(7.9,9.1)$ & $11.6(10.8,12.5)$ & $13.4(12.4,14.3)$ & $15.9(14.4,17.3)$ & $12.1(11.3,12.8)$ & $18.6(18,19.2)$ \\
\hline Secondary & $4.3(4,4.6)$ & $6.2(5.9,6.6)$ & $9.2(8.8,9.6)$ & $11.8(11.3-12.3)$ & $14.2(13.6-14.8)$ & $11.9(11.6-12.3)$ & $18.5(18.1-18.9)$ \\
\hline Higher & $3.6(2.4-4.8)$ & $4.3(3.5-5.1)$ & $6.5(5.8-7.3)$ & $9.3(8.6-9.9)$ & $13.1(12.4-13.7)$ & $12.4(11.5-13.3)$ & $13.5(13-14)$ \\
\hline \multicolumn{8}{|l|}{ Age group } \\
\hline 15-19 & $1.5(1.3-1.7)$ & $2.2(1.9-2.4)$ & $2.4(2.1-2.7)$ & $2.4(2.1-2.7)$ & $3.1(2.5-3.6)$ & $1.6(1.3-2)$ & $11.5(10.8-12.2)$ \\
\hline $20-24$ & $5(4.6-5.4)$ & $6.6(6.1-7.1)$ & $8.1(7.4-8.7)$ & 8.5 (7.9-9.1) & $7.8(7.2-8.3)$ & $3.4(2.9-3.9)$ & $7.4(7.2-7.7)$ \\
\hline $25-34$ & $6.5(6.1-6.9)$ & $9.2(8.8-9.7)$ & $12(11.4-12.5)$ & $13.9(13.2-14.5)$ & $15.6(14.9-16.3)$ & $11.4(10.9-11.9)$ & $15.4(15.1-15.7)$ \\
\hline $35-49$ & $6.6(6.3-6.9)$ & $9.3(8.9-9.7)$ & $12.8(12.2-13.3)$ & $15.7(15.1-16.3)$ & $19(18.3-19.7)$ & $15.8(15.3-16.3)$ & $18.9(18.5-19.3)$ \\
\hline \multicolumn{8}{|c|}{ Employment status } \\
\hline Not in workforce & $5.2(4.6-5.8)$ & $6.5(5.8-7.1)$ & $10.1(9.3-10.9)$ & $11.6(10.8-12.4)$ & $14.4(13.4-15.4)$ & $11.8(11.1-12.6)$ & $18(17.4-18.7)$ \\
\hline Others & $7(6.3-7.8)$ & $9.7(8.6-10.7)$ & $12.7(11.3-14.1)$ & $13(11.6-14.4)$ & $16.3(14.4-18.1)$ & $14.6(13.9-15.3)$ & $12.4(11.5-13.3)$ \\
\hline \multicolumn{8}{|l|}{ Marital status } \\
\hline Currently married & $6.3(6.1-6.6)$ & $9.1(8.8-9.4)$ & $12.1(11.6-12.5)$ & $14.7(14.2-15.2)$ & $17.6(17-18.2)$ & $14.1(13.8-14.4)$ & $18.3(18-18.6)$ \\
\hline Other & $2.1(1.9-2.3)$ & $2.5(2.3-2.7)$ & $3.7(3.4-4)$ & $3.7(3.4-4.1)$ & $4.5(4.1-4.9)$ & $3.0(2.7-3.3)$ & $13.7(13.2-14.3)$ \\
\hline
\end{tabular}

All subgroups were statistically significant at $p<0.05$ and values have been rounded to one decimal place. The largest magnitude of wealth-related inequality for each dimension has been bold

group (1.6), 'other than married' (2.4). The absolute $\mathrm{q}_{5}-$ $\mathrm{q}_{1}$ difference in BE coverage among 'OBC group' was 9.3 percentage points (highest amongst all caste groups) and the ratio was 2.9 indicating three times higher coverage in the richest quintile than the poorest quintile. The pattern by education, in contrast, was mixed: the poorest women with higher education had lower BE coverage (3.6\%, 95\% CI: 2.4, 4.8) and the wealthiest women with primary education had highest BE coverage (15.9\%, 95\% CI: 14.4, 17.3). The absolute $\mathrm{q}_{5}-\mathrm{q}_{1}$ difference (10.6) was highest among women with primary education while the ratio (3.6) was highest in women with higher education levels. The Absolute $\mathrm{q}_{5}-\mathrm{q}_{1}$ difference (12.4) in age group for $\mathrm{BE}$ coverage was highest in the 35-49 age group and the ratio was 3 indicating that the richest quintile had three times higher $\mathrm{BE}$ coverage than the poorest quintile. As expected, BE coverage was lowest among those aged 15-19 across all quintiles. Employed women reported greater $\mathrm{BE}$ coverage than unemployed women across bottom three quintiles. The absolute $\mathrm{q}_{5}-\mathrm{q}_{1}$ difference in $\mathrm{BE}$ coverage by employment was insignificant in top two quintiles. BE Coverage among currently married women ranged from $6.3 \%$ in poorest quintile to $17.6 \%$ in richest quintile as compared to $2.1 \%$ in poorest quintile to only $4.5 \%$ in richest quintile among those not married. Among married women, $\mathrm{BE}$ coverage was three times higher in richest quintile than poorest quintile while among 'other than married' quintile, it was two times higher.

\section{Summary measures of inequality}

When looking at summary measures, we found statistically significant wealth inequality in breast examination across all intersecting subgroup dimensions. All the SIIs and RCIs were positive, meaning that breast examination coverage was concentrated among wealthier quintiles regardless of place of residence, religion, caste and tribal 

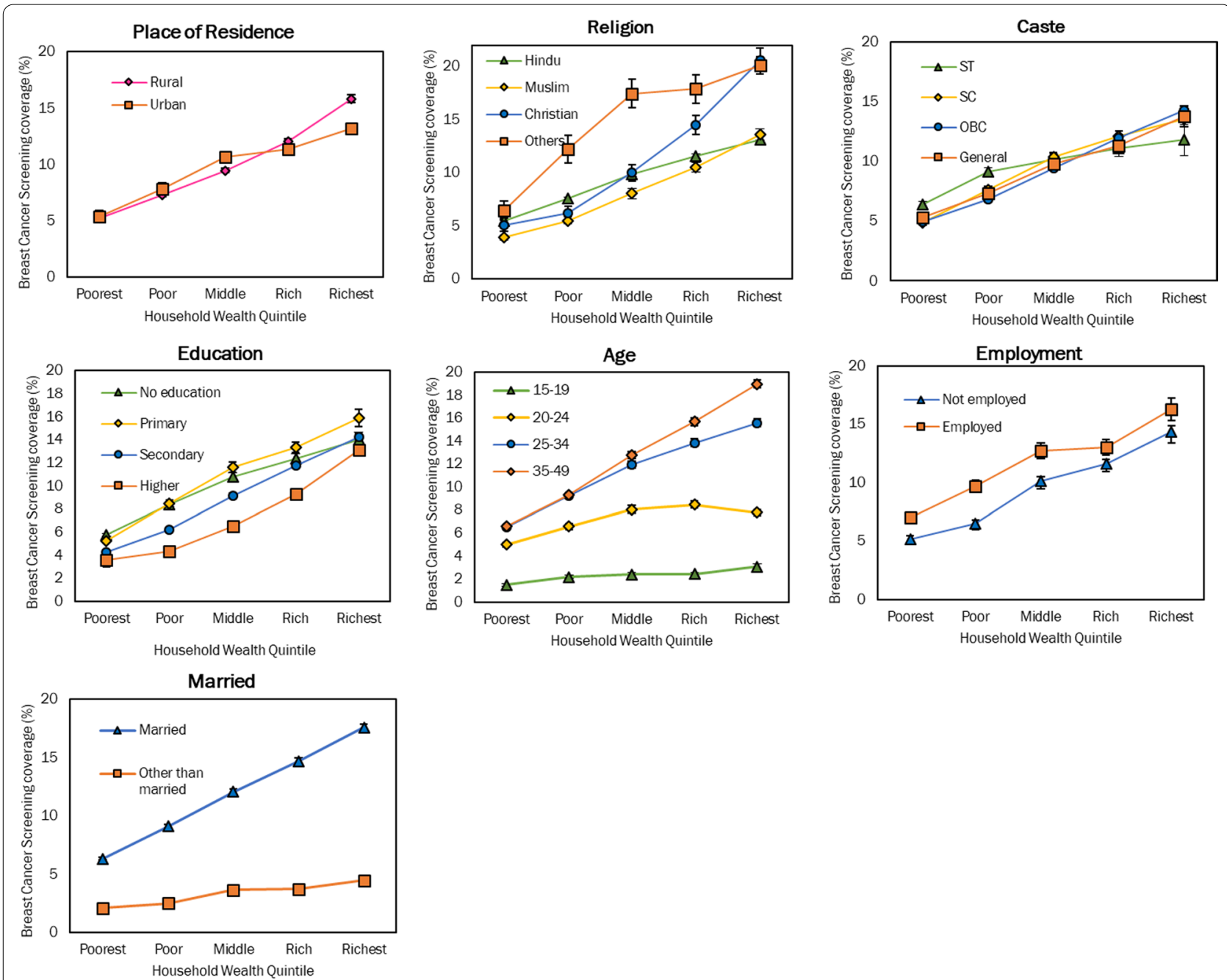

Fig. 1 BE coverage (\%) disaggregated by dimensions of inequality

group, education, age, employment status and marital status (Table 3).

Our absolute and relative measure were generally consistent with each other (see Table 1). Looking at SII, the greatest wealth-related inequalities in breast examination coverage were seen among Christians (SII: 20.6, 95\% CI: 18.5-22.7). Across other dimensions, we saw significantly greater inequality in rural areas (SII: 10.8, 95\% CI: 10.511.1), among SC (SII: 10.8, 95\% CI: 10.2-11.3), OBC (SII: 11.7, 95\% CI: 11.3-12.1), and other general populations (SII: 13.9, 95\% CI:13.5-14.3), as compared to ST groups (SII: 7.0, 95\% CI: 6.2, 7.7), among groups with education (SII: 12.4, 95\% CI:11.5, 13.3), as compared to those without (SII: 9.5, 95\% CI: 9.0, 9.9), among those aged 25-34 (SII: 11.4, 95\% CI: 10.9, 11.9), and 35-49 (SII: 15.8, 95\% CI: 15.3, 16.3), as compared to younger populations, among the employed (SII:14.6, 95\% CI:13.9, 15.3), compared to those not, and those married as compared to those not (SII: 3.0, 95\% CI:2.7, 3.3). We saw the same general pattern with the RCI for place of residence, religion, caste and tribal group, age-group and marital status, although for education, the magnitude of wealth-related inequality in BE coverage among primary \& secondary educated women was higher relative to those with higher levels or no of education. We also saw a higher magnitude of wealth related inequality in BE coverage among those not in the workforce in comparison to those who were.

\section{Discussion}

To best of our knowledge, this study is the first of its kind which measures inequality in $\mathrm{BE}$ coverage using double disaggregation. We examined wealth-related inequalities in $\mathrm{BrCa}$ screening coverage of Indian woman intersecting with place of residence, religion, age, employment and marital status. One of the most interesting findings of 
our study was that BE coverage was concentrated among wealthier groups across all population subgroups. This strongly relates with the fact that a woman's economic status largely influences her decision and ability to access screening.

Importantly, the magnitude of wealth-related inequality varied by sub-dimensions. Some studies conducted in upper and middle income countries have reported that marital, socio- economic level and educational status have significant associations with the utilization of BrCa screening services [31-34]. We found large wealth related inequalities among Christians, Muslims, rural women closely followed by $35-49$ age group, OBC and SC groups, primary and secondary educated groups, married and unemployed groups.

Higher Income levels has been reported as an important factor for uptake of $\mathrm{BrCa}$ screening services in most of the studies but their interplay with different social subgroups is complex. The results of this study show that although residing in rural areas is associated with greater $\mathrm{BE}$ coverage when compared to residing in urban areas, yet higher wealth related inequality persists among rural women in comparison to urban women. A study assessing social determinants in $\mathrm{BrCa}$ screening among women of age 40-69 years from 15 developing countries found that among women residing in rural areas, middle socio economic status (SES) household had reduced likelihood of $\mathrm{BrCa}$ screening in comparison to high SES household [35]. A study using the same data source as ours, assessing $\mathrm{BrCa}$ screening uptake in districts found that residing in rural areas in addition to being married, belonging to general caste and higher income status contribute positively to utilization of $\mathrm{BrCa}$ screening services [2]. A cluster randomised controlled cohort study in Mumbai reported that increasing age, Muslim religion, higher education, higher-income, single unmarried women were identified as predictors for non-compliance to screening [18].

We also found increasing age was significantly associated with the uptake of undergoing breast examination in our study but a coverage reported among the younger age group in our study [15-25] may be either suggestive of margin of error in self-report of BE or instrumentation issues, as the likelihood of a $\mathrm{BE}$ in this age group is extremely low. Additionally, in the present study, we found that Muslim and Christian women had highest wealth-related inequality in $\mathrm{BE}$ coverage, with coverage concentrated among wealthier populations. Cultural and religious beliefs often interweave to form distinctive traditions and rules which affect women's decision to participate in screening $[36,37]$. These may be more concentrated among poorer households as compared to wealthier households, resulting in a wealth gradient. In a breast cancer screening trial conducted in 2006 in Trivandrum, Kerala, India, findings were similar to our study: adjusted results showed that Christians were about $40 \%$ less likely to attend breast clinics than Hindus [16]. This study also reported that women who were not currently married were significantly less likely to participate in any level of screening process than married women. Another cross sectional study in a district in Kerala interviewing 809 women found that age 35-50 years, marriage, and employment were significant predictors of uptake in $\mathrm{BrCa}$ screening [19]. Findings from a systematic review of BrCa screening uptake in LMICs showed that religion, education, lack of accessibility, lack of knowledge about the diseases and screening were considerable barriers to BrCa screening in women [15].

In most of the studies, being married and employed were found to be associated with an increase in utilization of $\mathrm{BrCa}$ screening. corroborating the results of our study. However, it is also important to note that we also found large magnitudes of wealth-related inequalities in $\mathrm{BE}$ coverage among those married or employed suggesting that screening is concentrated among the well-off women from these subgroups. This is of concern because a recent systematic review found that non-married women are at greater risk of $\mathrm{BrCa}$ [38].

Women with primary and secondary education levels had higher magnitude of relative wealth-related inequality in $\mathrm{BE}$ coverage compared to those with higher education while the absolute inequalities were nearly the same. The literature suggests that households with less education may have lower awareness of the advantages of getting screened for cancer [35]. Importantly, the study showed that magnitude of inequalities may differ when measuring them in absolute or relative terms. Additionally, a qualitative study conducted in rural Andhra Pradesh to understand physician's perspective on screening methods followed by women diagnosed with breast cancer reflected that awareness of screening is limited to higher socioeconomic groups [20]. A community-based study where screening programme of women age 30-64 was implemented in urban slums of Mumbai, India found that literacy was a positive predictor of participation in screening while belonging to Muslim religion was a negative predictors of participation in screening [17, 18]. The interplay of education and wealth status is underexplored in the literature and warrants further study in relation to $\mathrm{BrCa}$.

A previous study has also reported economic status and education as leading predictors of participation in BrCa screening [35], although their interplay was not explored. A systematic review conducted in 2017 examining $\mathrm{BrCa}$ screening barriers reported lack of breast cancer knowledge, and an inadequate understanding of 
the screening role as the key barriers of women's screening participation in LMICs, noting also that $\mathrm{BrCa}$ is not a health priority in LMICs, resulting in screening programmes being either opportunistic or not present at all [15]. As aforementioned, population-based screening for $\mathrm{BrCa}$ in India was put in place only after 2016. The fifth round of NFHS is in the process of being completed; it will be important to see how the magnitude of socioeconomic inequalities has changed after the launch of the national screening program. Routine screening may be a significant intervention to control $\mathrm{BrCa}$ and improve outcomes, especially in LMICs like India where BrCa mortality is high, and access to mammography is much lower compared to high income country settings. As screening access is sought to be improved, it will be important to ensure socio-demographic, socio-economic, geographic and other inequalities do not fragment this access.

There are some limitations in this study. Firstly, the age group of study is restricted to 15-49-year-old women because NFHS provides data for this reproductive age group only (In the 15-19 age group, screening was reported-3\% of the youngest age group [15-24], suggestive of non-sampling and instrumentation errors). Secondly, the data did not enable us to differentiate between who got screened for preventive purposes and who got screened after getting the disease itself. Thirdly, the data did not allow us to differentiate between women receiving screening through the government initiatives and those getting screening willingly. Further, in this analysis, we examined inequalities, but without data on consent and choice, we were not able to ascertain whether inequalities were unjust or preventable, and thus unable to take a view on whether they represent inequities.

\section{Conclusions}

Breast examination coverage in India is concentrated among wealthier populations across populations groups defined by place of residence, religion, age, employment and marital status. Apart from this national analysis, subnational analyses may also help with identifying strategies for programme rollout and to ensure equity in women's cancer screening. Findings further suggest that more culturally appropriate awareness campaigns especially among low socioeconomic households are needed to increase screening participation and compliance. There is also a need to monitor gaps in coverage as the ongoing population-based screening programme advances.

\footnotetext{
Abbreviations

NFHS: National Family Health Survey; BE: Breast examination; SII: Slope index for inequality; RCI: Relative Concentration Index; BrCa: Breast cancer; ST: Schedule tribe; SC: Scheduled caste; OBC: Other backward classes; HEAT: Health equity assessment toolkit.
}

\section{Supplementary Information}

The online version contains supplementary material available at https://doi. org/10.1186/s12905-021-01464-5.

Additional file 1. Results of multiple logistic regression analysis of Breast Cancer Screening

\section{Acknowledgements}

We are grateful to Anne Schlotheuber and Dr. Ahmad Reza Hosseinpoor from the Health Equity Monitoring team at World Health Organization for their inputs regarding our methods and findings.

\section{Authors' contributions}

DN conceptualized the idea of the research paper. JN analysed the data and prepared the first draft of the paper. JN and DN were equally involved in editing and reviewing the paper. Both the authors read and approved the manuscript.

\section{Funding}

This work was supported by the Wellcome Trust/DBT India Alliance Fellowship (grant number IA/CPHI/16/1/502653) awarded to Dr Devaki Nambiar.

\section{Availability of data and materials}

All datasets used for supporting the conclusions of this paper are free to download using a short registration form at demographic health surveys website: at https://www.dhsprogram.com/data/Using-DataSets-for-Analysis. cfm\#CP_JUMP_14037.

\section{Declarations}

Ethics approval and consent to participate Not applicable.

\section{Consent for publication}

Not applicable.

\section{Competing interests}

The authors declare that they have no competing interests.

\section{Author details}

${ }^{1}$ Independent Consultant, 62 Stratford Rd, Kensington, California 94707, USA. ${ }^{2}$ The George Institute for Global Health, New Delhi, India. ${ }^{3}$ Faculty of Medicine, University of New South Wales, Sydney, Australia. ${ }^{4}$ Prasanna School of Public Health, Manipal Academy of Higher Education, Manipal, India.

Received: 26 May 2021 Accepted: 14 August 2021

Published online: 07 September 2021

\section{References}

1. International Agency for Research on Cancer WHO: Latest global cancer data: Cancer burden rises to 18.1 million new cases and 9.6 million cancer deaths in 2018. In: 2018

2. Mishra R, Monica M: An epidemiological study of cervical and breast screening in India: district-level analysis. BMC Women's Health 2020.

3. DM P, SL W, J F, H S: Cancer incidence in five continents. In: Volumes I to VIII. International Agency for Research on Cancer Lyon, France; 2005.

4. Ginsburg O, Rositch A, Conteh L, Mutebi M, Paskett E, Subramanian S. Breast cancer disparities among women in low-and middle-income countries. Curr Breast Cancer Rep. 2018;10(3):179-86.

5. Singh Sandeep Shrivastava JP. Dwivedi Ankit Breast cancer screening existence in India: A nonexisting reality. Indian J Med Paediatr Oncol. 2015;36(4):207

6. American Cancer Society SR: Cancer Fact and Figures 2020. In: 2020.

7. Globocan: Incidence, Mortality and Prevalence by cancer site. In: International Agency for Research on Cancer India. World Health Organisation; 2020. 
8. Sankaranarayanan R, Alwan N, Denny L. How can we improve survival from breast cancer in developing countries? Breast Cancer Manag. 2013;2(3):179-83.

9. Ministry of Health and Family Welfare G: National Family Health Survey (NFHS-4). In. Mumbai: IIPS; 2015-2016.

10. Oeffinger KC, Fontham ET, Etzioni R, Herzig A, Michaelson JS, Shih Y-CT, Walter LC, Church TR, Flowers CR, LaMonte SJ. Breast cancer screening for women at average risk: 2015 guideline update from the American Cancer Society. JAMA. 2015:314(15):1599-614.

11. Breast Cancer: prevention and control. https://www.who.int/cancer/ detection/breastcancer/en/.

12. Mittra I, Mishra GA, Dikshit RP, Gupta S, Kulkarni VY, Shaikh HKA, Shastri SS, Hawaldar R, Gupta S, Pramesh C: Effect of screening by clinical breast examination on breast cancer incidence and mortality after 20 years: prospective, cluster randomised controlled trial in Mumbai. BMJ 2021, 372.

13. Ministry of Health and Family Welfare Gol: Operational Guidelines on Prevention Screening and Control of Common Non Communicable Diseases. In: 2016

14. Vidyarthi ASA, Choudhary S, Sinha BK. Barriers to breast cancer screening in young Indian women: a tale of two cities. Asian J Exp Sci. 2013;27:29-35.

15. Islam RM, Billah B, Hossain MN, Oldroyd J. Barriers to cervical cancer and breast cancer screening uptake in low-income and middle-income countries: a systematic review. Asian Pac J Cancer Prev APJCP. 2017;18(7):1751.

16. Frie KG, Ramadas K, Anju G, Mathew BS, Muwonge R, Sauvaget C, Thara $\mathrm{S}$, Sankaranarayanan $\mathrm{R}$. Determinants of participation in a breast cancer screening trial in Trivandrum district, India. Asian Pac J Cancer Prev. 2013;14(12):7301-7.

17. Kulkarni SV, Mishra GA, Dusane RR: Determinants of compliance to breast cancer screening and referral in low socio-economic regions of urban India. Int J Prev Med 2019;10.

18. Dinshaw K, Mishra G, Shastri S, Badwe R, Kerkar R, Ramani S, Thakur M, Uplap P, Kakade A, Gupta S. Determinants of compliance in a cluster randomised controlled trial on screening of breast and cervix cancer in Mumbai, India. Oncology. 2007;73(3-4):145-53.

19. Sreedevi A, Quereshi MA, Kurian B, Kamalamma L. Screening for breast cancer in a low middle income country: predictors in a rural area of Kerala, India. Asian Pac J Cancer Prev. 2014;15(5):1919-24.

20. Bodapati SL, Babu GR. Oncologist perspectives on breast cancer screening in India-results from a qualitative study in Andhra Pradesh. Asian Pac J Cancer Prev. 2013;14(10):5817-23.

21. Shrivastava S, Shrivastava PS, Ramasamy J. Self-breast examination: a tool for early diagnosis of breast cancer. Am J Public Health Res. 2013;1(6):135-9.

22. Pruitt SL, Shim MJ, Mullen PD, Vernon SW, Amick BC. Association of area socioeconomic status and breast, cervical, and colorectal cancer screening: a systematic review. Cancer Epidemiol Prev Biomark. 2009;18(10):2579-99.

23. Jain AK, Nandy P. Breast cancer prevention and management: Evidence and possibility in India. J Med Sci Res. 2019;10:33.
24. Beining RM. Screening for cervical cancer: an exploratory study of urban women in Tamil Nadu. lowa: University of lowa; 2012.

25. Joe W. Intersectional inequalities in immunization in India, 1992-1993 to 2005-2006: a progress assessment. Health Policy Plan. 2014;30(4):407-22.

26. Iyer A, Sen G, Östlin P. The intersections of gender and class in health status and health care. Glob Public Health. 2008;3(S1):13-24.

27. Iyer A, Sen G, George A. The dynamics of gender and class in access to health care: Evidence from rural Karnataka. India Int J Health Serv. 2007;37(3):537-54

28. StataCorp: Stata Statistical Software: Release 12 College Station, TX: StataCorp LLC. In: 2010.

29. Reza Hosseinpoor A, Nambiar D, Schlotheuber A, Reidpath D. Ross Z: Health equity assessment toolkit (HEAT): software for exploring and comparing health inequalities in countries. BMC Med Res Methodol 2016.

30. Health Equity Assessment Toolkit Plus (HEAT Plus): Software for exploring and comparing health inequalities in countries. In: Upload database edition. Version 4.0. Geneva, World Health Organization, 2021.

31. Deandrea S, Molina-Barceló A, Uluturk A, Moreno J, Neamtiu L, PeiróPérez R, Saz-Parkinson Z, Lopez-Alcalde J, Lerda D, Salas D. Presence, characteristics and equity of access to breast cancer screening programmes in 27 European countries in 2010 and 2014. Results from an international survey. Prev Med. 2016;91:250-63.

32. Yavari P, Pourhoseingholi MA. Socioeconomic factors association with knowledge and practice of breast self-examination among Iranian women. Asian Pac J Cancer Prev. 2007;8(4):618-22.

33. Lin S-J. Factors influencing the uptake of screening services for breast and cervical cancer in Taiwan. J R Soc Promot Health. 2008;128(6):327-34.

34. Martín-López R, Jiménez-García R, Lopez-de-Andres A, Hernández-Barrera V, Jiménez-Trujillo I, Gil-de-Miguel A, Carrasco-Garrido PJPh. Inequalities in uptake of breast cancer screening in Spain: analysis of a cross-sectional national survey. Elsevier. 2013;127(9):822-7.

35. Akinyemiju TF. Socio-economic and health access determinants of breast and cervical cancer screening in low-income countries: analysis of the World Health Survey. PLOS ONE. 2012;7(11):e48834

36. Shah SM, Ayash C, Pharaon NA, Gany FM. Arab American immigrants in New York: health care and cancer knowledge, attitudes, and beliefs. J Immigr Minor Health. 2008;10(5):429-36.

37. Vahabi M, Lofters A, Kim E, Wong JPH, Ellison L, Graves E, Glazier RH. Breast cancer screening utilization among women from Muslim majority countries in Ontario, Canada. Prev Med. 2017;105:176-83.

38. Li M, Han M, Chen Z, Tang Y, Ma J, Zhang Z, Liu Z, Zhang N, Xi C, Liu J. Does marital status correlate with the female breast cancer risk? A systematic review and meta-analysis of observational studies. PLOS ONE. 2020;15(3):e0229899.

\section{Publisher's Note}

Springer Nature remains neutral with regard to jurisdictional claims in published maps and institutional affiliations.

Ready to submit your research? Choose BMC and benefit from

- fast, convenient online submission

- thorough peer review by experienced researchers in your field

- rapid publication on acceptance

- support for research data, including large and complex data types

- gold Open Access which fosters wider collaboration and increased citations

- maximum visibility for your research: over 100M website views per year

At BMC, research is always in progress.

Learn more biomedcentral.com/submissions 